\title{
Green chemistry with nanocatalysts
}

\author{
John A. Glaser
}

(C) Springer-Verlag (outside the USA) 2012

Nano matter is expected to be a fruitful area for green chemistry catalysis due the increasing ability to design in the nano state and the high surface areas found in nano materials. Nanocatalysts are esteemed as materials of enormous surface areas and with new research, developments may offer expanding catalytic capabilities. The iron catalyst BASF-S6-10 has recently been developed for application in the Haber-Bosch ammonia synthesis process. With a surface area of $20 \mathrm{~m}^{2} / \mathrm{g}$, the catalyst is deployed as nanometer-sized particles containing reduced iron oxide in a framework of $\mathrm{Al}_{2} \mathrm{O}_{3}$ and $\mathrm{CaO}$ to stabilize the catalyst against agglomerization.

$\mathrm{N}_{2}+\mathrm{H}_{2} \stackrel{\text { BASF-S60-10 }}{\longrightarrow} \mathrm{NH}_{3}$

Nanocatalysts are heralded as new process candidates exhibiting higher activity, greater stability, durability or recycling potential, efficient recovery characteristics, and cost effectiveness. These new catalysts are candidates for clean energy applications such as hydrogen generation, hydrogen storage and fuel cell applications. One promising use is for the synthesis of hydrogen peroxide.

$\mathrm{H}_{2}+\mathrm{O}_{2} \rightarrow \mathrm{H}_{2} \mathrm{O}_{2}$

Separation of the nanocatalyst from the reaction media can become daunting due to the catalyst particle size. The use of magnetically separable supports for the nanocatalyst can aid the efficient recovery of the catalyst. Advancing structures for homogeneous catalyst can be designed for

J. A. Glaser $(\bowtie)$

US Environmental Protection Agency, National Risk

Management Research Laboratory, 26 W King Dr, Cincinnati, OH 45268, USA

e-mail: Glaser.John@epa.gov clean energy applications including hydrogenation, hydrogen storage, and fuel cells.

ChemSusChem 2012, 5, 65-75

\section{Green synthetic power of enzymes}

ACS Chemical Reviews has published a special 400+ page issue entitled: Enzymes in Synthesis containing eleven chapters on subjects ranging from precision and stereoselective syntheses to designed enzyme applications to organic synthesis. The eleven chapter set is organized as a guidebook to newcomers to the discipline. Against the backdrop of an accelerating proliferation of publications devoted to enzyme use for chemical production, the issue editor finds the use of biocatalysts to conduct organic synthesis to be virtually nonexistent within the US academic community and offers a current assessment of this developing area of modern synthetic strategy. He also asserts that biocatalysts offer remarkable features to facilitate "green chemistry" conversions or syntheses. With these obvious credentials, enzymatic catalysis is surprisingly missing from the enunciated twelve principles of green chemistry. The new perspectives of chemical biology and related areas of synthetic research have not established a strong footing within the community of organic chemists due to a general phobia to the use of biological methods. Yet, a slate of significant biological methods conducted at large scale in industry leading to products such as insulin and erythromycin have already been utilized. One example of the issue's contents can be seen in the use of a selected transaminase in the synthesis of sitagliptin. This reaction converts a ketone functionality to a chiral amine through enantioselective means. 


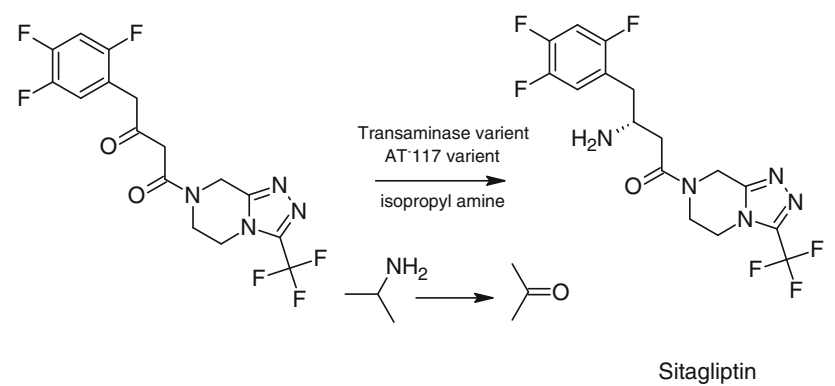

Chem Rev 2011, 111, 3995-4404

\section{Chemical production at small-scale}

A provocative perspective asks the small-scale chemical producer to re-evaluate the basic operations model for fine chemical production. Batch processes dominate small-scale production processes for fine chemicals and pharmaceuticals. Incomplete knowledge of relevant scalable technology specific to the desired chemical process becomes highly limiting. Production at continuous small-scale can achieve ton per year scale quantities. At 8,000 h/year, continuous production of $0.1-10 \mathrm{~kg} / \mathrm{h}$ yields $0.8-80 \mathrm{t} / \mathrm{a}$. Other process related advantages for continuous production are offered for consideration. One area of obvious application of this thinking is the utilization of microreaction equipment. In this development, the conversion of existing batch process requires an evaluation of each reaction to determine whether the reaction conditions are sufficiently versatile to accommodate the change. Laboratory experimentation will be required to garner the necessary data to convert to continuous operation. It will be interesting to see if this perspective of process downsizing gains traction in the fine and pharmaceutical chemical industry.

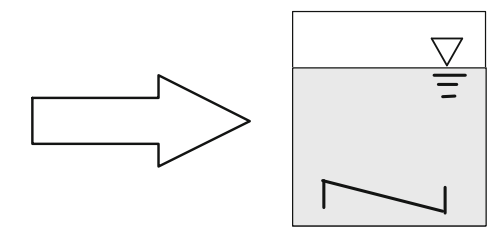

Batch process

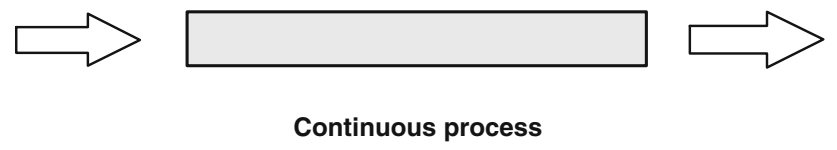

Chem Ing Tech 2011, 9, 1337-1342

\section{Plastic recycling conversion technology}

In 2010, 31 million tons of plastic waste were generated in the US representing $12.4 \%$ of the total municipal solid waste (MSW). However, only $8 \%$ of the total plastic waste generated in 2010 was recovered for recycling. The American Chemistry Council has recently released a 65 page report entitled Environmental and Economic Analysis of Emerging Plastic Conversion Technologies authored by RTI International which shows the benefits of new technologies that convert plastic into energy and raw materials. Some 41 facilities are under development or engaged in technology demonstration. The report focused on thermal waste conversion technologies including pyrolysis and gasification. Pyrolysis thermally decomposes carbonaceous material without the use of oxygen to form products for steam and electricity generation. There are other directions to use the product stream from pyrolysis too. Gasification involves heating the waste at high temperatures to form hydrocarbon raw materials. Pyrolytic technologies were found to be suited to handling waste plastic feedstocks whereas gasification technologies were more suited to MSW. The conversion technologies are envisioned to attain commercial viability in the 5-10 year horizon. Plastics-to-oil technologies are found to be closer to commercialization than gasification of MSW. A life-cycle environmental review found that waste conversion technologies exhibit stronger environmental benefits than land fill disposal. For instance, plastic pyrolysis could save 1.8-3.6 MMBtu/ton when compared with land fill disposal. Economic and non-economic drivers exert significant influence over the waste conversion technologies. Onehundred plastics-to-energy conversion facilities could offset 6,000-18,000 barrels of oil each day. The report cautions there is a "high level of uncertainty" in the environmental and cost data cited for the facilities evaluated in the report since none were currently operating commercially.

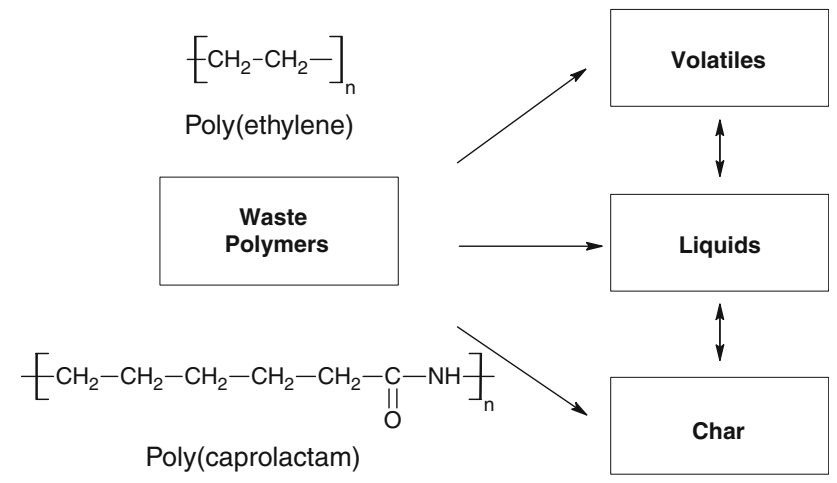

http://plastics.americanchemistry.com/Sustainability-Recycling/ Energy-Recovery/Environmental-and-Economic-Analysisof-Emerging-Plastics-Conversion-Technologies.pdf

http://plastics.americanchemistry.com/Plastics-to-Oil 


\section{Biofuels for transportation}

The carbon neutral status of biofuels for transportation is considered a major asset but the implication of land use related to the generation of the requisite biomass remains a significant issue. The joint production of ethanol and electricity for transportation from a sugar cane refinery was analyzed for benefits and drawbacks. Currently available cost competitive technology was scrutinized for the impact of cane sugar-based biofuel production on land use. The results show the land requirement to power current transportation needs to be less than previously stated. Using Brazilian sugar based production, 2 million ha of land was required to power the automobile use needs for 2010. To provide the needs of the US auto fleet, an estimated 25 million ha are required and the global auto fleet needs can be met through the use of 67 million ha. With minor indicate that this material is a strong candidate as an absorber of $\mathrm{CO}_{2}$ from the large exhaust gas flows associated with electrical power generation. A variety of emerging methods designed to capture and store $\mathrm{CO}_{2}$ are under development. Such technologies include metal organic frameworks, zeolitic polymer networks, and nanoporous organic polymer frameworks. Selectivity for $\mathrm{CO}_{2}$ capture is important due to the volume and chemical mixture of exhaust gases.

The triptycene benzimidazole-linked polymers are synthesized through the slow addition of suitable aryl aldehydes to 2,3,6,7,14,15-hexaaminotriptycene and are isolated as yellow powders. The rate of aldehyde addition was found to strongly enhance pore formation and overall porosity. The high $\mathrm{CO}_{2}$ uptake and selectivity of the triptycene derived polymers suggests as roles post-combustion $\mathrm{CO}_{2}$ absorbents.

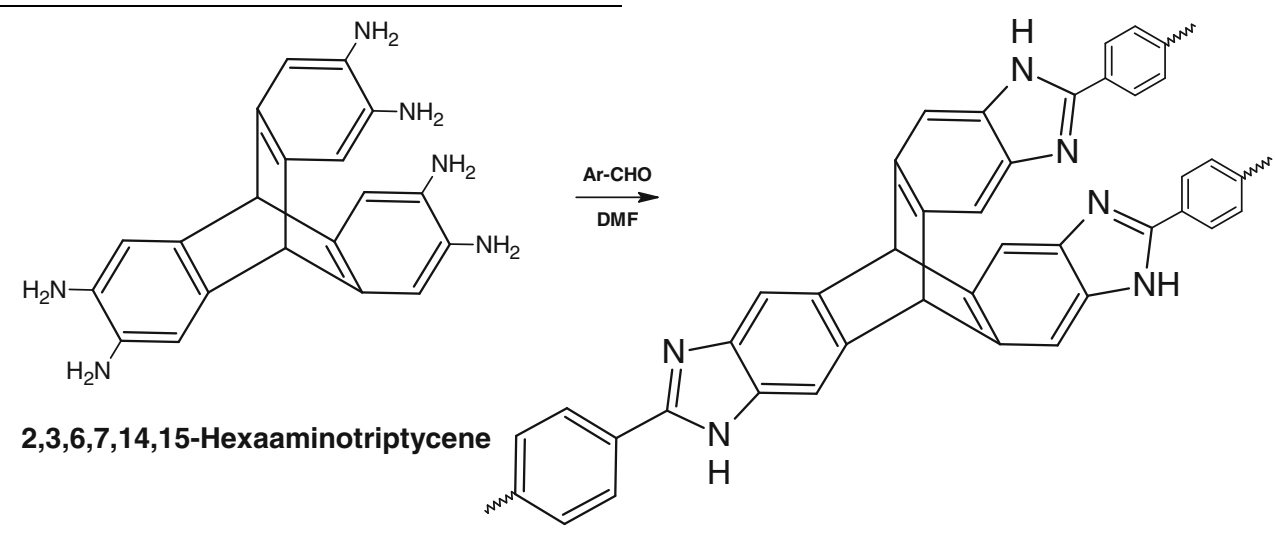

Triptycene-derived benzimidazole-linked polymers

changes to process efficiency, 18 million ha can provide the fuel for the US auto fleet in 2030. The report used a harvested energy density of $306 \mathrm{GJ} / \mathrm{ha} /$ year. The assumptions of utilizing a sugar cane mill for energy production, an internal combustion hybrid auto with $15 \mathrm{~km} / \mathrm{L}$ fuel use efficiency and an electrical vehicle with a $6.5 \mathrm{~km} / \mathrm{kWh}$ efficiency. These remarkable projections contrast a series of similar land use projections for a variety of biomass sources. The report's findings are eye opening and hopefully lead to a more comprehensive evaluation of biomass sources for fuel production.

Environ Sci Technol 2011, 54, 9498-9505

\section{Designer $\mathrm{CO}_{2}$ trapping polymers}

Benzimidazole-linked polymers formed from a triptycene monomer have been found to have high $\mathrm{CO}_{2}$ uptake. Remarkable selectivity for $\mathrm{CO}_{2}$ against $\mathrm{N}_{2}$ and $\mathrm{CH}_{4}$
Chem Comm 2012, 48, 1141-1143

http://portal.acs.org/portal/acs/corg/content?_nfpb=true\&_ pageLabel=PP_ARTICLEMAIN\&node_id=222\&content_ id=CNBP_029649\&use_sec=true \&sec_url_var=region $1 \&$ _uuid=715ab3b5-7330-47da-8884-828728353974

\section{Catalysis in the pharmaceutical industry}

The use of catalysis in the chemical industry is widespread. Catalytic processes are implicit to the production of more than $90 \%$ of chemicals in commerce today. The global catalyst demand per year was estimated as $\sim 850,000$ tons in 2007 and is expected to increase by $\sim 4 \%$ in 2012. By contrast, stoichiometric, non-selective chemical transformations conducted with catalyst can increase the yield of the desired product with significant waste reduction.

One example of the application of catalysts to industrially significant needs can be found in the synthesis of (-)- 
menthol. Supplies of (-)-menthol from natural sources are insufficient to meet the market demand which is also affected by weather and geopolitical issues. A steady market supply is available through a BASF process that provides thousands of metric tons of menthol each year for the global market. using phase transfer catalysis, boronic acid-catalyzed dehydration, and hydrogen bonding catalysis.

Adv Synth Catal 2011, 353, 1825-1864
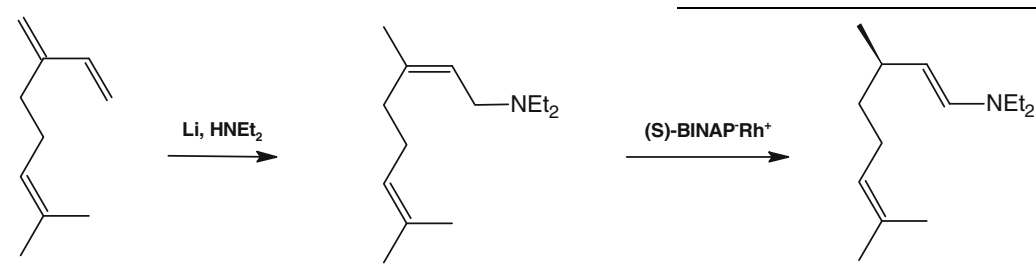

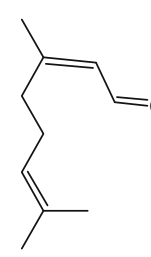

BASF process

neral

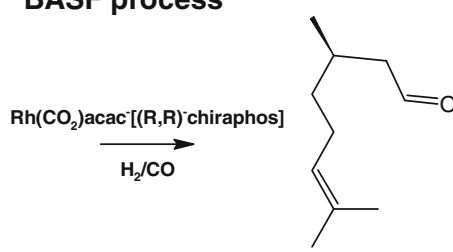

(R)-citronellal

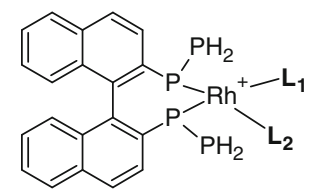

(S)-BINAP'Rh ${ }^{+}$
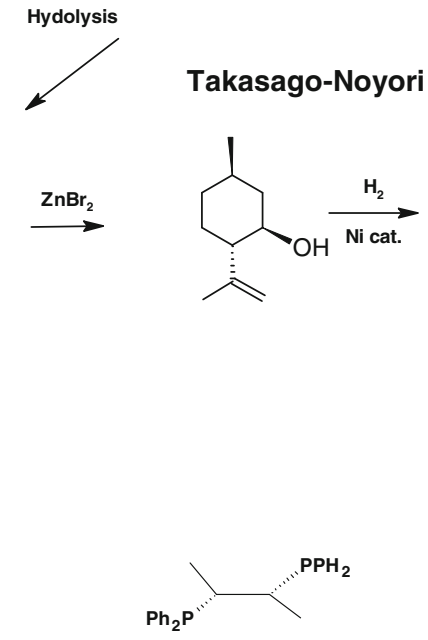

(R,R)-chiraphos
This review underscores the increasing number of ways for catalysts to offer industrial synthetic pathways to biologically active compounds. In the transition metal-catalyzed reaction category, there are several established application areas such as asymmetric hydrogenation, addition reactions, metathesis reactions, oxidation, and crosscoupling reactions. One notable hydrogenation process is the synthesis of metolachlor. This herbicide, used to protect maize crops, was originally produced as a mixture of four isomers. These isomers can be subdivided into two sets of diastereomers and one set was identified as having the biocidal activity. By carefully selecting reaction conditions, the biologically active set of diastereomers could be produced exclusively. Consequently, the reduced amount of herbicide required for control was reduced by more than $40 \%$ due to the elimination of the biologically inactive isomers form the final product. Enzyme catalyzed reactions are delineated in terms of designer enzymes and joint catalysis using transition-metal catalysts and enzymes. Organocatalysis is focused in chiral amine catalysis, organocatalyzed asymmetric epoxidation, asymmetric alkylation

\section{Future of green chemistry}

Industrial biotechnology is seen by the authors as a contributor to green industrial chemistry. The criteria of green chemistry are met through the use of biocatalysis. There are admittedly significant limitations where these approaches are used in industry. Significant examples show the emerging prowess of biosynthesis with detailed applications to biologically active chemicals. Vitamin $\mathrm{B}_{12}$ is found in nearly all organisms as a biologically active compound. In humans, $\mathrm{B}_{12}$ is required for red blood cell formation, neurological function, and DNA synthesis in trace quantities of $2.4-3.0 \mu \mathrm{g}$ each day at a purity of 96-98\%. Chemical synthetic pathways to $\mathrm{B}_{12}$ require 70-steps but two biosynthetic approaches can accomplish synthesis in 9 days or less utilizing selected microorganisms under fermentation conditions. Eco-efficiency analysis of different chemical or biotechnological $B_{12}$ synthetic technologies show the biotechnology processes to have high eco-efficiency when compared with the chemical process. 


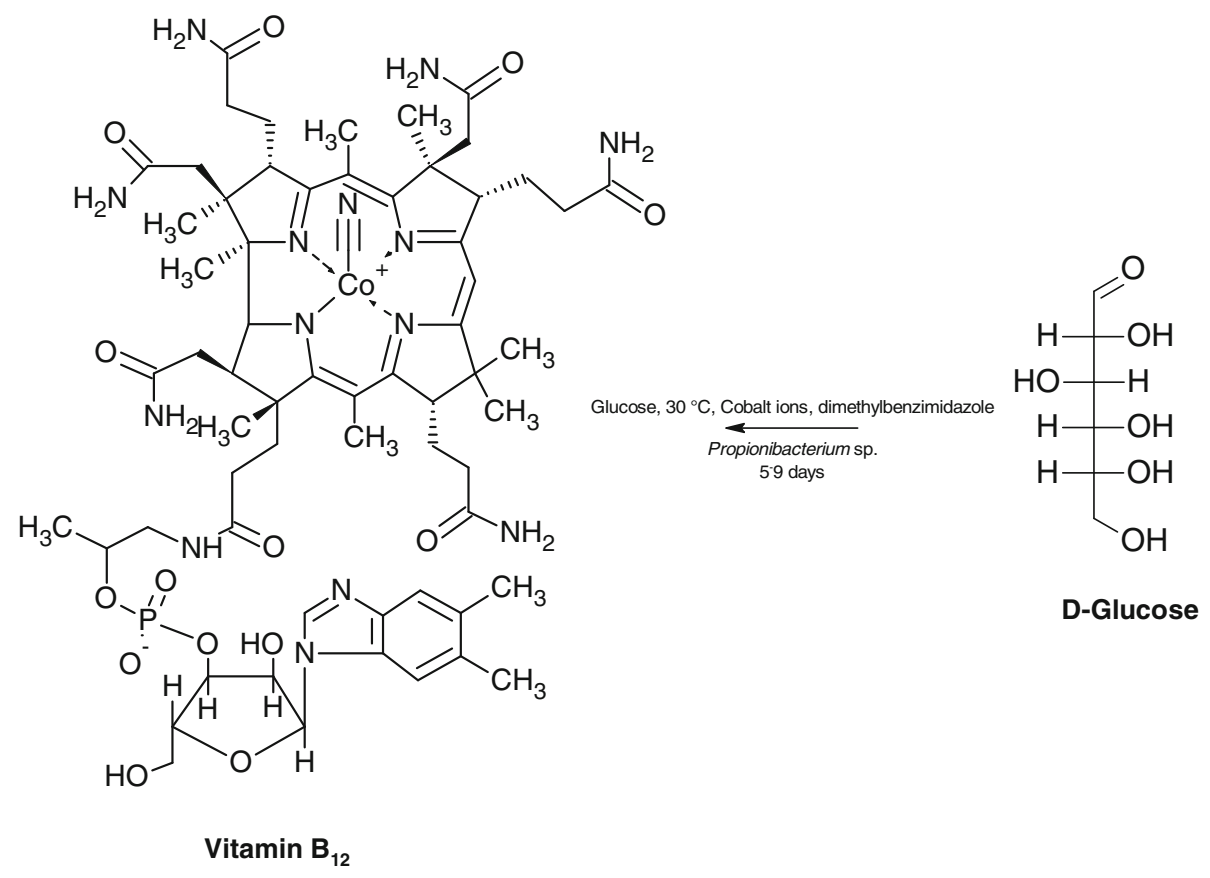

Green Chem 2011, 13, 3007-3047

\section{Green chemistry initiatives flourishing}

News from a recent American Chemical Society (ACS) Green Chemistry and Engineering conference shows the investments made by many innovative companies in embracing green chemistry due to considerations of environmental sustainability, increased efficiency, and reduced costs. Green chemistry is gaining prominence through global expectations for sustainable use of resources, and responsive to the precautionary and risk adverse interests of stockholders. In the US, eighteen states have passed some 71 chemical control laws since 2003 focused on the implementation of green chemistry, data collection, and phased out and/or reduced industrial use of toxic chemicals. One contributor offered that "Green chemistry is good chemistry." An example of the these principles is to be found in the Pfizer synthesis of the antidepressant sertraline $\left(\right.$ Zoloft $\left.^{\circledR}\right)$. An effort to streamline the original three-step process to produce the pure chiral sertraline was improve to enhance the product yield and selectivity. The optimized process was accomplished through raw material usage in the range of 20-60\% for each of the three chemicals employed. Solvent recovery was improved through the use of ethanol to replace four hazardous solvents. Waste control for the process has found means to double the product yield, eliminate 2 million lbs. of chemical wastes yearly, reduce energy consumption, and enhance safety and material handling.<smiles>CNC1(C)CCC(C)(c2ccc(Cl)c(Cl)c2)c2ccccc21</smiles>

The ACS Green Chemistry Institute Pharmaceutical Centered Roundtable (GCIPR) formed from a broad representation of the pharmaceutical industry has accomplished some remarkable achievements. A GCIPR funded research grant program based on green chemistry principles has funded academic liaisons with industry. Roundtable members have individually pioneered areas of green chemistry and advancement through the implementation of recent successful strategies. One notable contribution of GCIPR is seen in the influence exerted on ACS Organic Process Research and development to avoid publishing papers using benzene or chloroform as reaction solvents or used in the workup.

Gen Eng News 2011, 31(19), 34, 36

\section{Skyfarming}

The effects of climate change are estimated to reduce $10 \%$ of the land currently under cultivation for every $1^{\circ}$ of temperature increase. Major changes to agricultural cultivation are anticipated during the next 50 years when the 
increasing demand for food necessities will grow at a pace where the burgeoning global population requirements may exceed production capabilities. Demand for an expansion of cultivated land and intensification of agricultural practices will tax agricultural production worldwide. One novel approach to answering this demand is found in recent proposals for vertical farm development. Reflection on the inadequacies of a roof top garden led to an idea of the vertical farm. Buildings could be functionally constructed to provide the necessary space and sun exposure to make such a proposal a reality. Using materials such as ethylene tetrafluoroethylene polymer as a self-cleaning transparent film could assist the construction of a high-tech vertical farm having functional beauty. Extensions of this basic theme to provide skyfarm constructs can be viewed as an ecological innovation with a potential for making significant contributions to enhancing global food security. Where human population density is high as in cities, the vertical farm concept may play a significant role. Much of the supporting technology is available to test these concepts and it is expected that proof-of-concept examples will be available soon.

J Verbr Lebensm (J Consum Protect Food Safety) 2011, 6, 233-236; 237-251

\section{E. coli as a nanorecorder}

An emerging area of biotechnology, synthetic biology unifies molecular biology, genetic engineering and protein engineering. The raw materials of synthetic biology are DNA, RNA and proteins whereas synthetic chemistry uses small molecule chemicals and catalysts as raw materials. Synthetic bacteria have been designed and constructed recently to provide novel or un-natural functions to fill knowledge gaps relating to natural biological systems. Proof-of-principle demonstrations have been conducted to embody many of the recent discoveries. Useful applications continue to emerge and one of recent exciting example is the development of a nanorecorder that can detect, record, and time stamp the detection event.

A facile modification of an existing genetic toggle switch has been exploited to fabricate a robust biological trait that could function as a recording device at the microbial or nano level over a broad timeframe to a wide range of chemical stimuli.

A novel E. coli strain was constructed using a synthetic chemical sensitive toggle switch to activate fluorescent protein indicators and a cell division inhibitor to provide a simple recording device. The toggle switch construct can detect and store the "memory" of a stimulating event but a time stamp was not possible for past constructs. This research shows how a biological "nanorecorder" could be functionally developed to detect, and record a response to a wide range of chemical stimuli varying with time and space. This interesting development shows the current level of sophistication applied to the inventions of synthetic biology. These findings begin to expose the very fruitful results that allow for a better evaluation of the future prospects of synthetic biology. Applications of this technology to environmental issues/problems are expected to have a multitude number of applications and can be viewed as benign and sustainable.

PLoS ONE 6(11), e27559. doi:10.1371/journal.pone.0027 559

\section{Synthetic biology disaster avoidance}

The ecological risks associated with synthetic microbes have received strong comment from a group of interested parties. Global markets for synthetic biology are expected to expand aggressively with the success of current research efforts. The 2010 market was estimated to be \$1.1 billion US/year with an expectation to reach $\$ 10.8$ billion US by 2016 due mainly to chemical and energy applications. Four areas of risk valuation are recommended for consideration: organisms will react with the environmental surrounding through their physiology and differences between the synthetic and natural organisms will modulate the interaction with the environment, the survivability of the synthetic organisms will be important to long term concerns, the new synthetic organisms are expected to occupy different/new ecological niches, and gene transfer between the synthetic organism and the environment. Many of these concerns have been addressed during the vetting of similar concerns for genetically modified microorganisms in technologies such as bioremediation. This earlier review has shown the release of the GM microbes did not present a threat to the environment. The current direction of concern comes from the Synthetic Biology Project at the Woodrow Wilson International Center for Scholars in Washington DC. A workshop was held during 2011 to address the general concerns perceived for synthetic biology. Ecologists and synthetic biologists contributed at the meeting to help move the new research field forward while being attentive to ecological impacts. The new organisms are seen to be altered in more sophisticated ways thereby offering problems with monitoring, management, and regulation as the new technology is introduced to the environment.

A rather different perspective is offered by an advocate of this new research field. His article "The Organism is the Product" clearly states his enthusiasm for the new developments. He emphasizes the work of Genomatica in their report 
of developing a new industrial microbe to convert sugars into 1,4-butanediol in the span of 3 years. He asserts that it is now possible for companies without prior experience in bioconversion technology to expand their business through the deployment of an engineered-microbe. Should this turn of events be realistic, the conversion of sugar feedstocks to produce higher value chemicals may be realized. Clearly, the current reported successes offer a vista of what may be possible with this new technology in the near future.

It will be interesting to see how these perspectives are engaged and properly exploited to provide new sustainable technology and protect the environment.

Nature 2011, 483, 29; ACS Synth Biol 2012, 1, 4-5

\section{Subsidy independence for clean technology}

The Brookings Institute has released a new report entitled: Beyond Boom \& Bust: Putting Clean Tech on a Path to Subsidy Independence with the World Resources Institute and Breakthrough Institute as coauthors. The effects of US federal funding changes due to expiring subsidies are found to be critical to the advancement of the clean technology sector. Without legislative action, federal funding for clean energy technology could fall by $75 \%$ to $\$ 11$ billion in 2014. The 2009 American Recovery and Reinvestment Act, funding a host of technology development and testing programs, is anticipated to expire leading to a greater than $50 \%$ reduction. Production tax credits are expected to end in the 2012-2013 timeframe. The Brookings report sets a series of objectives to productively react to these funding challenges to put clean energy technology on a developmental path of subsidy independence.

http://www.brookings.edu/ /media/Files/rc/papers/2012/ 0418_clean_investments/0418_clean_investments_final\% 20paper_PDF.pdf.

\section{Green innovation index}

The state of California has adopted policies and laws supporting the development of clean energy technology designed to reduce pollutant emissions. Next 10, has issued the 68 page 2012 California Green Innovation Index which the 4th edition of an annual analysis of key factors including energy productivity, active clean energy technology patents, emissions relative to economic growth, and venture capital investments to this technology area. The non-partisan group, NEXT 10 is focused on the enhancement of innovation addressing the solution of California's environmental pollutant emissions and related issues. This year's index tracks the relation of pollutant emissions on the economy, energy productivity, venture capital investments, and patents describing clean technology inventions and applications in this context. Clean technology patents increased by $41 \%$ in the period from 2005-2007 to 2008-2010. Venture capital investment in clean technology increased to $24 \%$ of the total US venture capital investment. California has $29 \%$ of the US solar capacity due to recent utility-scale solar installations. California wind generation capacity grew $44 \%$ in the period 2009-2010. The analysis asserts that California emitted $28 \%$ less carbon for the latest reporting period than in 1990 for every dollar in 2009 gross domestic product. Energy productivity, ratio of consumed energy to GDP, is $64 \%$ lower in California than in the other 49 states. This efficiency is comparable to Japan, Germany and the UK. The savings related to this enhanced efficiency can be reinvested into the state economy through a variety of investments. The report investigated California's desire to enhance the use of renewable energy. The state has enunciated goals to derive $33 \%$ of their electricity from solar, wind, and other renewable energy sources.

http://www.next10.org/sites/next10.huang.radicaldesigns. org/files/2012_GII\%20Report_R6.pdf

\section{Ozone and particulate standards exceeded}

The American Lung Association has recently released a 175 page report, State of the Air 2012 showing that $41 \%$ of the US population resides in counties where the air quality exceeds current air quality standards for airborne concentrations of particulates and ozone. The report found that for the period of 2001-2010 certain aspects are improving such as ozone pollution decreased by $13 \%$ whereas annual particulate matter concentrations dropped by $24 \%$ with the daily particulate pollution falling by $28 \%$. The elevated air pollution concentrations indicate that poor health statistics should correlate with these high concentrations. It is remarkable that the US should experience the extent of air pollution indicated by these results in the context of the US leadership in environmental matters.

http://www.stateoftheair.org/2012/assets/state-of-the-air2012. pdf.

\section{New journals}

Materials for Renewable and Sustainable Energy is a peerreviewed Open Access journal without author charges covering experimental and theoretical aspects of energy 
evaluated in the context of enabling technologies leading to renewable and sustainable pathways for the future. Batteries, biofuels, fuel cells solar fuels, and $\mathrm{CO}_{2}$ sequestration are among the topics under consideration for this new journal.

http://www.journals.elsevier.com/nano-energy/

Nano Energy is a peer-reviewed multidisciplinary, original rapid-publication focused on nanomaterials and nanodevices related to energy harvesting, conversion, storage, utilization and power. Acceptable subject topics range from batteries to thermoelectric devices. The new journal espouses a goal of comprehensive coverage of a new field of discovery uniting nanoscience and nanotechnology with energy science.

http://www.journals.elsevier.com/nano-energy/ 